\title{
Effects of Astragaloside IV Against the TGF- $\beta 1$-Induced Epithelial-to-Mesenchymal Transition in Peritoneal Mesothelial Cells by Promoting Smad 7 Expression
}

\author{
Lu Zhang ${ }^{a, b}$ Zhenghong $\mathrm{Li}^{\mathrm{b}}$ Weiming $\mathrm{He}^{\mathrm{b}}$ Lingdong $\mathrm{Xu}^{\mathrm{b}} \quad$ Jing Wang ${ }^{\mathrm{c}}$ Jun Shi \\ Meixiao Sheng ${ }^{a, b}$ \\ ${ }^{a}$ First Clinical Medical College, Nanjing University of Chinese Medicine, Nanjing, ${ }^{b}$ Renal Division, \\ Affiliated Hospital of Nanjing University of Chinese Medicine, Jiangsu Province Hospital of Chinese \\ Medicine, Nanjing, cliangsu Province Academy of Traditional Chinese Medicine, Nanjing, China
}

\section{Key Words}

Astragaloside IV • TGF- $\beta 1$ - Smad7 • EMT - Mesothelial cells - Peritoneal dialysis (PD) • Peritoneal fibrosis (PF)

\begin{abstract}
Background/Aims: To investigate the effect of Astragaloside IV (AS-IV) on the regulation of the TGF- $\beta 1 /$ Smad signaling pathway in peritoneal mesothelial cells with an epithelial-tomesenchymal transition (EMT). Methods: EMT of human peritoneal mesothelial cells (HMrSV5) was induced using $2 \mathrm{ng} / \mathrm{ml}$ TGF- $\beta 1$. Cells were randomly divided into a vehicle group, a vehicle group with AS-IV, a TGF- $\beta 1$ treated group, and a TGF- $\beta 1$ treated group receiving varied doses of AS-IV or NAC. Real-time quantitative PCR and western blot were used to detect the expression of genes and proteins associated with the TGF- $\beta 1 / \mathrm{Smad}$ signaling pathway and EMT. DCFHDA was used to detect the generation of ROS in HMrSV5 cells, and a transwell migration assay was used to verify the capacity of AS-IV to inhibit EMT in HMrSV5 cells. Lentiviruses were used as carriers for the overexpression or knockdown of the Smad7 gene. Results: Expression levels of E-cadherin (epithelial marker) was decreased and vimentin, $\alpha$-SMA (EMT markers) and collagen I (extracellular matrix protein) phospho-Smad2/3, Snail1 and Snail2 was increased significantly in the TGF- $\beta 1$-treated HMrSV5 cells. AS-IV was associated with downregulated expression of vimentin and phospho-Smad2/3 in a dose-dependent manner, while the expression of Smad7 increased. Silenced or forced expression of Smad7 verified its role in the inhibitory effect of AS-IV on TGF- $\beta 1$-induced EMT in HMrSV5 cells. Conclusion: AS-IV effectively promotes the upregulation of Smad7 in the TGF- $\beta 1 / S m a d$ signaling pathway during the EMT of HMrSV5 cells, indicating its potential therapeutic effect for the control of PF.
\end{abstract}




\section{Cellular Physiology Cell Physiol Biochem 2015;37:43-54 \begin{tabular}{l|l|l}
\hline DOI: 10.1159/000430332 & C 2015 S. Karger AG, Basel
\end{tabular} and BiOChemistry $\frac{\text { Published online: August 12, } 2015}{\text { Zhang et al.: AS-IV Against the TGF- } \beta 1 \text {-Induced EMT }}$

\section{Introduction}

Continuous ambulatory peritoneal dialysis (CAPD) has become widespread in patients with end-stage renal disease because peritoneal dialysis (PD) patients exhibit better survival compared with hemodialysis (HD) patients during the first 2 years of dialysis treatment [1]. However, long-term exposure to PD fluid and recurrent episodes of peritonitis result in morphologic and functional changes of the peritoneal membrane, also known as peritoneal fibrosis (PF) [2]. Pathologic changes in the peritoneal membrane include a loss of the mesothelial cell layer and a thickening of the submesothelial layer that features increased myofibroblasts, collagen deposition, and new blood vessels [3-5]. These changes to the peritoneal membrane ultimately contribute to ultrafiltration failure, resulting in technique failure and discontinuation of PD therapy [6]. Consequently, the most important challenge currently faced in PD is the prevention of PF and the long-term preservation of peritoneal membrane structure and function [7].

Interestingly, various traditional Chinese medicine materials have been shown to safely suppress the pro-inflammatory and pro-fibrotic pathway and control PF in several in vivo and/or in vitro studies [8-10]. Astragaloside IV (AS-IV, shown in Fig. 1) is a saponin purified from Astragalus membranaceus that has been routinely used to treat various diseases in China [11]. It has been reported that AS-IV has healing and anti-scar effects on wound repair, and the accepted underlying mechanisms include both promoting angiogenesis and collagen synthesis and decreasing the levels of collagen I/III and TGF- $\beta 1$ secretion by fibroblasts [12]. Moreover, AS-IV shows anti-fibrotic effects on renal fibrosis, hepatic fibrogenesis and myocardial fibrosis [13-16].

Epithelial-to-mesenchymal transition (EMT), a reversible process in which epithelial cells transdifferentiate into cells with mesenchymal characteristics, is widely considered to be a crucial process in fibrosis $[17,18]$. EMT in mesothelial cells is a critical step in the pathogenesis of PF, and this process is essential for the development of encapsulating peritoneal sclerosis (EPS) [18-22]. However, the protective effects of AS-IV against EMT still need to be elucidated. It has been reported that several growth factor and cytokine factor signaling pathways (TGFß1, FGF, EGF, HGF, Wnt/ $\beta$-catenin, and Notch) participate in EMT [23]. We found that Astragalus membranaceus inhibited PD-induced PF via the TGF- $\beta$ pathway [8]. Here, we used TGF- $\beta 1$-induced EMT in mesothelial cells to investigate the role of AS-IV in EMT and to elucidate the underlying molecular mechanisms.

\section{Materials and Methods}

\section{Cell Lines, Culture Conditions and Treatment with Reagents}

Human peritoneal mesothelial cells (HMrSV5 cells ATCC) were cultured in DMEM supplemented with $10 \%(\mathrm{v} / \mathrm{v}$ ) heat-inactivated fetal calf serum (Invitrogen) and $100 \mathrm{U} / \mathrm{ml}$ penicillin/streptomycin (Invitrogen). Cells were maintained at $37^{\circ} \mathrm{C}$ in a humidified environment ( $5 \% \mathrm{CO} 2$ and $95 \%$ air), and the culture medium was replaced every 2 days. All experiments were carried out 24-48 h after cells were seeded in culture plates. Cells were permitted to attach for $24 \mathrm{~h}$ and to grow to $75 \%$ confluence. To induce EMT, HMrSV5 cells were treated with TGF- $\beta 1$ ( 2 ng/ml) (R\&D Systems, Minneapolis, MN) for the indicated times. AS-IV (Chiatai Qingchunbao Pharmaceutical) was dissolved in DMSO for a stock concentration of $10 \mathrm{mg} / \mathrm{ml}$. The highest final concentration of DMSO in the medium was $0.1 \%$ to avoid affecting cell viability. Except for transwell migration assays, all experiments were carried out after incubation for $24 \mathrm{~h}$.

\section{Cell viability assay}

Cell viability was measured in a 96-well plate using a quantitative colorimetric assay (counting kit-8 (CCK-8) assay kit; Dojindo, Kumamoto, Japan). Cells were seeded in 96-well plates in triplicate, and various treatments were applied to the wells. After these treatments, the CCK-8 solution $(10 \mu \mathrm{L})$ was added to each well and the wells were incubated for another $2 \mathrm{~h}$ at $37^{\circ} \mathrm{C}$. Absorbance was measured at $450 \mathrm{~nm}$ (Bio-Tek, Elx800, USA). 


\section{Cellular Physiology Cell Physiol Biochem 2015;37:43-54 \begin{tabular}{l|l|l} 
DOI: 10.1159/000430332 & (C) 2015 S. Karger AG, Basel
\end{tabular}

$R N A$ preparation and quantitative real-time $P C R$

Total RNA in treated cells was isolated using TRIzol reagent (Invitrogen) according to the manufacturer's instructions. RT was performed using the RevertAidTM First Strand cDNA Synthesis Kit (Fermentas, Ottawa, Canada) following the manufacturer's instructions. The random RT primer 5'- $(\mathrm{dN})$ 9-3' was used for the Snail1, Snail2, and GAPDH genes. The polymerase chain reaction (PCR) primers were designed as follows: Snail1 sense, 5'TAA TTG GGG CTC CGG CTA ACT-3', reverse, 5'-TTG CAG GTC GCT TCC TTA TTC-3'; Snail2 sense, 5'-ATA GAG TTG AGC CTG TGG GACAC-3', reverse, 5'-AGG Fig. 1. Chemical structure of Astragaloside IV(AS-IV).

GTC TCT GGT CTA CTG ATGTC-3'; GAPDH sense, 5'-TGC ACC ACC AAC TGC TTAGC-3', reverse, 5'- GGC ATG GAC TGT GGT CAT GAG-3'. S ABI SYBR Green Master Mix (Invitrogen) was used according to the manufacturer's protocol. All mRNA quantification data were normalized to human GAPDH as an endogenous control for mRNA detection. The data were processed using the $2^{-{ }^{\Delta \Delta} \mathrm{C} t}$ method.

\section{Western blotting}

Treated cells were rinsed three times with ice-cold PBS and lysed using RIPA buffer (Beyotime, Hangzhou, China) according to the manufacturer's instructions. The lysates were centrifuged at 12,000×g at $4^{\circ} \mathrm{C}$ for $10 \mathrm{~min}$, and the supernatants were used for western blotting. The protein concentration was measured using the BCA Protein Assay Kit (Thermo, USA). Equal amounts (25 $\mu \mathrm{g} / \mathrm{lane}$ ) of protein were subjected to $10 \%$ SDS-polyacrylamide gel electrophoresis and transferred onto polyvinylidene fluoride (PVDF) membranes (Millipore, Bedford, USA). The membranes were blocked with 5\% skim milk in TBST at room temperature for $2 \mathrm{~h}$ and then incubated with primary antibodies at $4^{\circ} \mathrm{C}$ overnight. The membranes were subsequently incubated with secondary horseradish peroxidase (HRP)-conjugated goat anti-mouse or anti-rabbit IgG (diluted 1:5,000) (Santa Cruz Biotechnology, Texas, USA) for $1 \mathrm{~h}$. Membranes were exposed using the ECL system (Millipore, Bedford, USA). The following primary antibodies were used: E-cadherin(Cell Signaling Technology, Boston, USA), Collagen I (Cell Signaling Technology, Boston, USA), phospho-Smad2/3 (Cell Signaling Technology, Boston, USA), Smad2/3 (Cell Signaling Technology, Boston, USA), vimentin (Cell Signaling Technology, Boston, USA), $\alpha$-SMA (Abcam, Cambridge, UK), TGFRB1 (Santa Cruz Biotechnology, Texas, USA), TGFRB2 (Santa Cruz Biotechnology, Texas, USA), Smad7 (Cell Signaling Technology, Boston, USA) and GAPDH (Cell Signaling Technology, Boston, USA). Expression levels were normalized to GAPDH.

\section{Cell infection}

To establish stable knockdown and overexpression cell lines, the lentiviral vectors $\mathrm{pLV-Smad7-inhibitor}$ (target sequence: 5’ AAGGTTGCATACTGAGCCAAG 3') and pLV- Smad7-overexpression (NM-005904), along with the packaging plasmid mix, were purchased from Shanghai GenePharma Co., Ltd (Shanghai, China). Individual plasmids and the packaging mix were co-transfected into HEK293TN packaging cell lines using Lipofectamine2000. The culture supernatant was concentrated using the Lenti-pac lentivirus concentration solution (Genecopoeia, Guangzhou, China). The control plasmid provided with the lentivirus kit was processed as described above to obtain the control pseudovirus (sequence: 5' GTCCCGGATACCTAATAAA 3'). HMrSV 5 cells were incubated with the lentiviruses in the presence of $2 \mu \mathrm{g} / \mathrm{mL}$ polybrene (Gibco, CA, USA) and were cultured with $2 \mu \mathrm{g} / \mathrm{mL}$ puromycin (Sigma, CA, USA) for at least $96 \mathrm{~h}$ to select the stably transfected cells.

\section{Transwell migration assay}

Cell migration was determined using a polycarbonate membrane cell culture insert (Costar, Corning Incorporated, NY) as previously described. Cells were resuspended in DMEM medium containing 1\% FBS and seeded onto the top of the wells at a density of $1 \times 10^{5}$ cells/well. Cells were allowed to migrate the pores on the culture insert filled with medium containing 10\% FBS for $6 \mathrm{~h}$. Non-migrating cells on the upper 


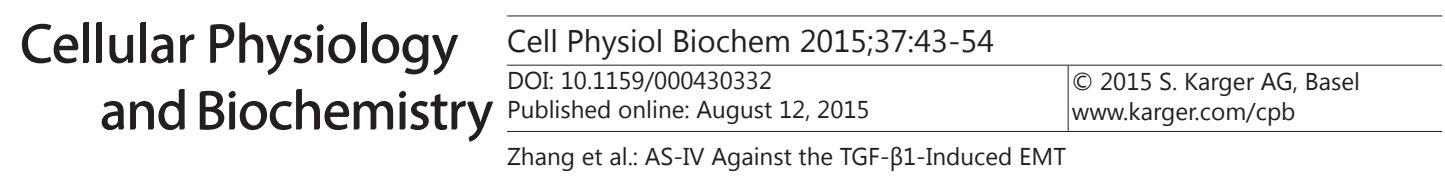

surface of the membrane were removed with a cotton swab, and the migrating cells on the lower surface of the membrane were fixed and stained with Giemsa. Migrating cells were counted using a microscope.

Measurement of ROS levels

Intracellular ROS generation was detected using 2', 7'-dichlorofluorescin diacetate (DCFH-DA) (KeyGEN Biotech, China). For measurement of intracellular ROS levels, cells were incubated for 15 min with 2.5 $\mu \mathrm{mol} / \mathrm{ml} \mathrm{DCFH2-DA}$ at $37^{\circ} \mathrm{C}$ for $30 \mathrm{~min}$ in the dark. After two washes with PBS, the cells were analyzed using a fluorescence microscope (Olympus BX 51, Tokyo, Japan). Cells with green fluorescence were considered ROS-positive cells. The mean fluorescence density of ROS generation was captured using a fluorescence microscope (Olympus BX51, Olympus, Tokyo, Japan) and processed using Image J software (NIH). At least 50 cells were randomly selected from a single captured field, and the average nuclear fluorescence intensity was calculated. Data points presented in the text are the averages calculated from five different fields..

\section{Statistical analysis}

Data from at least three independent experiments are presented as the means \pm standard error of the mean (SEM) using the SPSS 19.0 statistical software. The differences between treatment groups were analyzed using Student's t-test or one-way analysis of variance (ANOVA), followed by the Student-NewmanKeuls (SNK) test. P values of $<0.05$ from a two-tailed test were considered to indicate statistical significance.

\section{Results}

AS-IV had almost no effect on cell growth and apoptosis

According to the results from a CCK-8 assay, HMrSV5 cells treated with up to $400 \mu \mathrm{g} / \mathrm{ml}$ AS-IV for $72 \mathrm{~h}$ exhibited neither enhanced cell proliferation nor apoptosis (Fig. 2A and 2B).

AS-IV attenuates TGF $\beta 1$-induced EMT by inhibiting the activation of Smad2/3

After treatment with $2 \mathrm{ng} / \mathrm{ml}$ TGF $\beta 1$ for $24 \mathrm{~h}$, expression levels of E-cadherin was decreased and vimentin, $\alpha$-SMA and collagen I was increased markedly. These results were accompanied by enhanced expression of phospho-Smad2/3, indicating that activation of Smad2/3 is involved in TGF $\beta 1$-induced EMT and fibrosis. Pretreatment with AS-IV attenuated the activation of Smad2/3 and the expression of EMT and ECM markers in HMrSV5 cells (Fig. 3A-3F). These observations suggested that AS-IV treatment can inhibit TGF $\beta 1$-induced EMT via the Smad2/3 pathway. These results were also confirmed by the expression of Snail 1 and Snail2 mRNA (downstream of Smad2/3) (Fig. 3G and 3H).

A

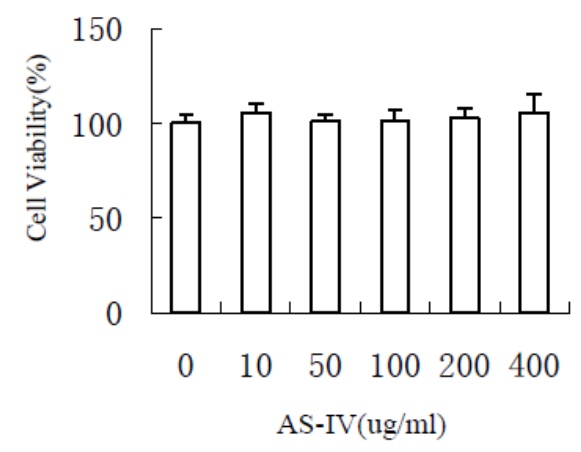

B

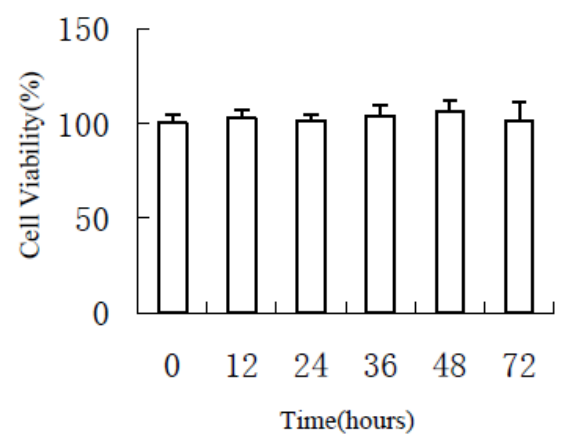

Fig. 2. Effect of AS-IV on HMrSV5 cell viability. Cells were treated with various dose of AS-IV (0, 10, 50, 100, 200 , and $400 \mu \mathrm{g} / \mathrm{ml}$ ) for $24 \mathrm{~h}(\mathrm{~A})$ or AS-IV $400 \mu \mathrm{g} / \mathrm{ml}$ for various times $(0,12,24,36,48$ and $72 \mathrm{~h})(B)$. Neither enhanced cell proliferation nor apoptosis were found in these cells. 


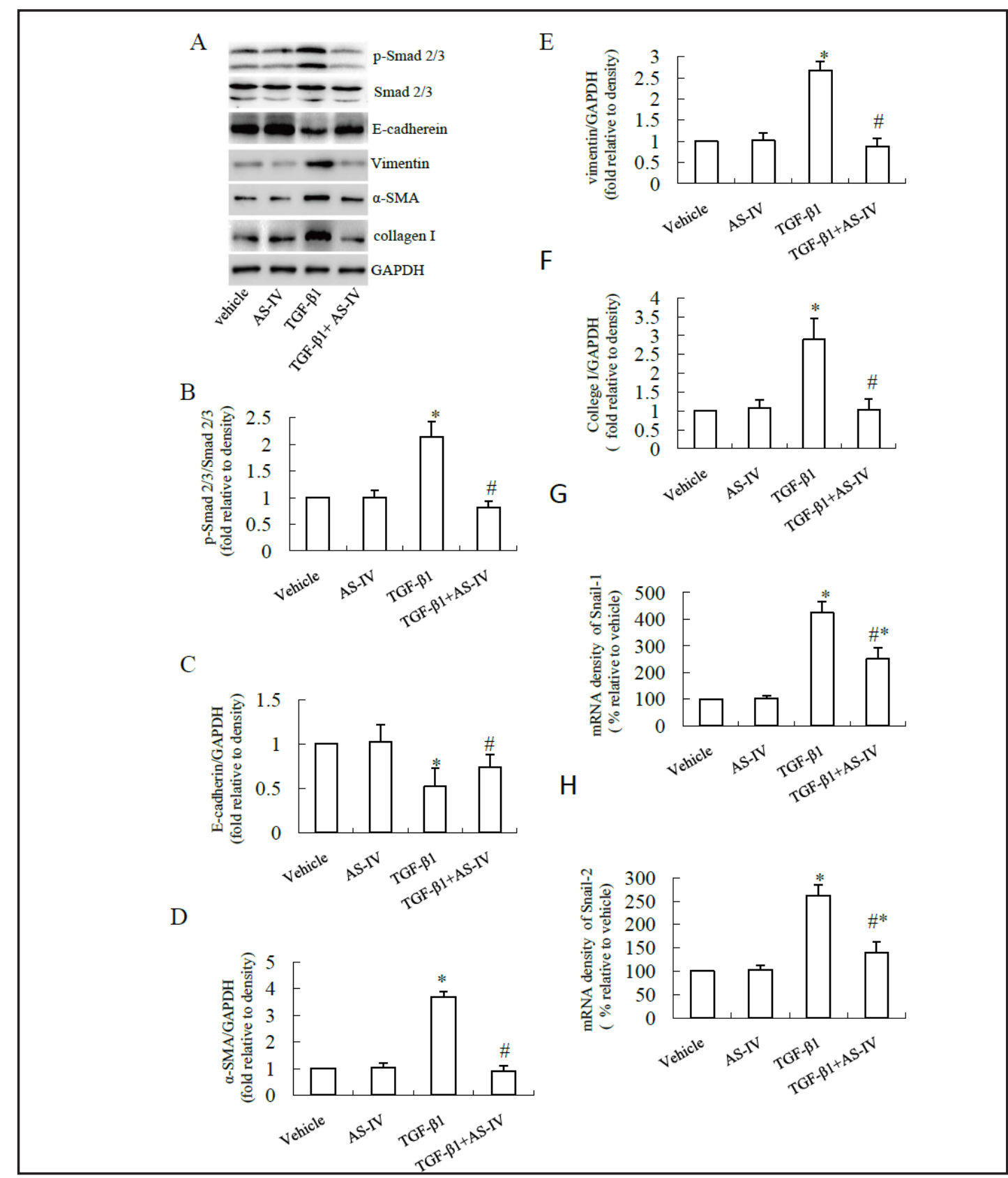

Fig. 3. Effect of AS-IV on TGF- $\beta 1$-induced activation of Smad2/3 and EMT in HMrSV5 cells. Cells were divided into a vehicle group (cells treated with $0.1 \%$ DMSO), a TGF- $\beta 1$ group (cells treated with $2 \mathrm{ng} / \mathrm{ml}$ TGF- $\beta 1$ ), an AS-IV group (cells treated with $400 \mu \mathrm{g} / \mathrm{ml}$ AS-IV) and an AS-IV + TGF- $\beta 1$ group (cells pretreated with AS-IV at $400 \mu \mathrm{g} / \mathrm{ml} 2 \mathrm{~h}$ prior to $2 \mathrm{ng} / \mathrm{ml}$ TGF- $\beta 1$ ). After incubation for $24 \mathrm{~h}$, cells were lysed using RIPA buffer or TRIzol reagent for a western blot assay and a quantitative real-time PCR assay, respectively. Representative immunoblots of p-Smad, Smad2/3, E-cadherin, Vimentin, $\alpha$-SMA, collagen I, and GAPDH in HMrSV5 cells under various treatments is shown in (A). GAPDH served as a loading control. Relative intensity of p-Smad/Smad2/3, E-cadherin/GAPDH, Vimentin/GAPDH, $\alpha$-SMA/GAPDH, collagen I/GAPDH is shown from (B) to (F). Expression of Snail1 and Snail2 mRNA in HMrSV5 cells under various treatments (G, H). ${ }^{*} \mathrm{p}<0.05$ vs. vehicle group, $\# \mathrm{p}<0.05$ vs. TGF- $\beta 1$ group, $n=3$.

\section{AS-IV attenuates Smad2/3 activation by enhancing expression of Smad 7}

Smad7 expression in TGF $\beta 1$-treated HMrSV 5 cells was enhanced by treatment with ASIV and was accompanied by decreased expression of phospho-Smad2/3 in a dose-dependent 


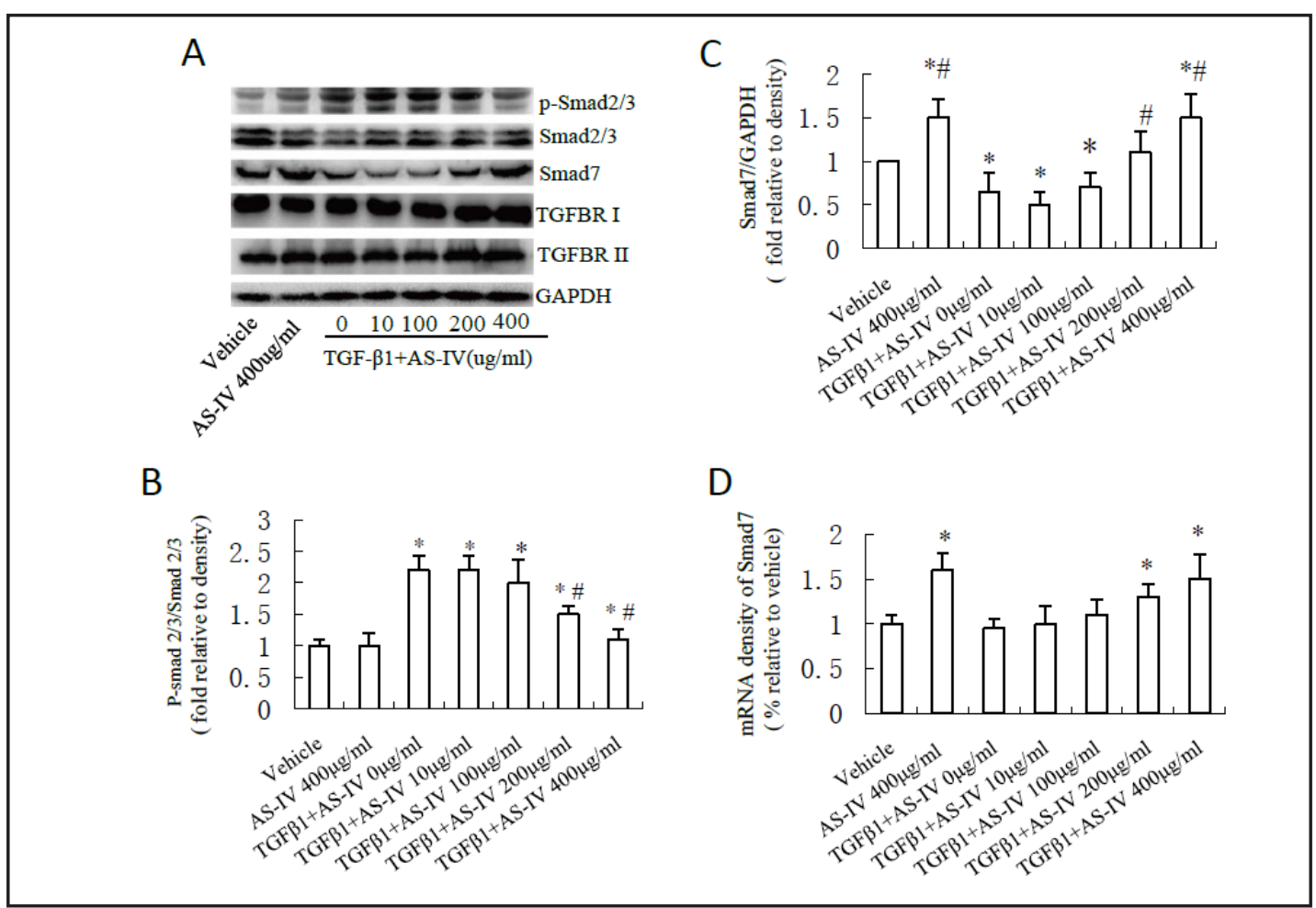

Fig. 4. Effect of AS-IV on TGF- $\beta 1$-induced activation of Smad2/3 and expression of Smad7, TGRBI and TGRBII in HMrSV5 cells. Cells were pretreated with AS-IV at various concentrations $(0,10,100,200,400$ $\mu \mathrm{g} / \mathrm{ml}) 2 \mathrm{~h}$ prior to $2 \mathrm{ng} / \mathrm{ml}$ TGF- $\beta 1$ treatment for $24 \mathrm{~h}$ and then lysed using RIPA buffer or TRIzol reagent for a western blot assay and a quantitative real-time PCR assay. The representative immunoblots of p-Smad, Smad2/3, Smad7, TGRBI, TGRBII and GAPDH in HMrSV5 cells under various treatments is shown in (A). GAPDH served as a loading control. Relative intensity of p-Smad/Smad2/3 and Smad7/GAPDH is shown in (B) and (C). Expression of Smad7 mRNA in HMrSV5 cells under various treatments is shown in (D) *p $<0.05$ vs. vehicle group, $\mathrm{n}=3$.

manner(Fig. 4A-4C) .Okado et al showed that Smad7 is induced by TGF- $\beta$ in mesangial cells [24]. However in present study, we did found AS-IV (200 and $400 \mathrm{ug} / \mathrm{ml}$ ) treatment upregulated the expression of Smad 7 both in mRNA and protein levels in HMrSV5 cells. TGF- $\beta 1$ reduced the Smad 7 expression in protein level but did not affect the expression of Smad 7 mRNA in HMrSV5 cells (Fig. 4D). Our results were different from previous literature [24]. This may be due to the difference between mesothelial cells and mesangial cells. As we expected, the expression of TGFBR1 and TGFBR2 did not change with either TGF $\beta 1$ or AS-IV treatment.

AS-IV-mediated attenuation of TGF $\beta 1$-induced EMT is independent of its antioxidant effect

After treatment with $2 \mathrm{ng} / \mathrm{ml}$ TGF $\beta 1$ for $24 \mathrm{~h}$, ROS levels were markedly increased. Both AS-IV and N-acetylcysteine (NAC, oxygen radical scavenger $100 \mathrm{nM}$ ) attenuated this increase (Fig. 5A and 5B), which indicated the antioxidant effect of AS-IV. However, NAC treatment did not affect the TGF $\beta 1$-induced activation of Smad2/3 and EMT in HMrSV5 cells (Fig. 5C$5 F$ ). These results suggested that AS-IV-mediated attenuation of TGF $\beta 1$-induced EMT is independent of its antioxidant effect.

Smad7 plays a key role in the inhibitory effect of AS-IV on TGF $\beta 1$-induced EMT

To further elucidate the function of Smad7 in the EMT, we generated stable cell lines using expressing Smad7 and Smad7 inhibitors or their scrambled controls with lentiviral constructs inducing or inhibiting Smad7 expression. Western blot analysis confirmed 


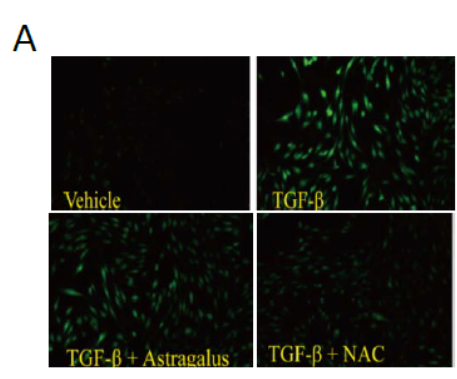

C

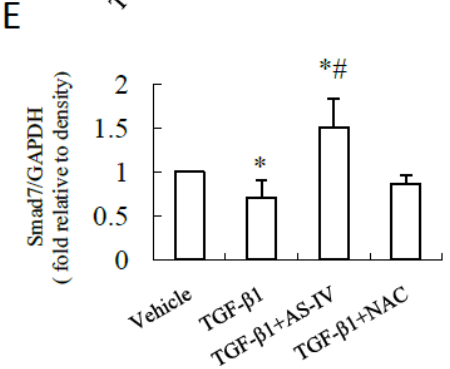

$\mathrm{B}$

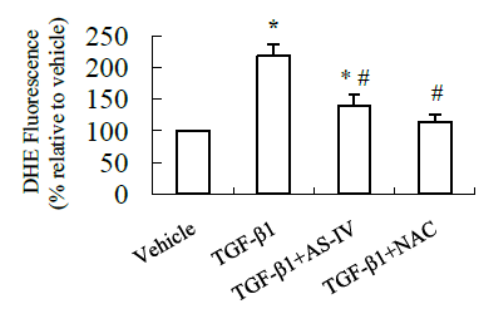

D

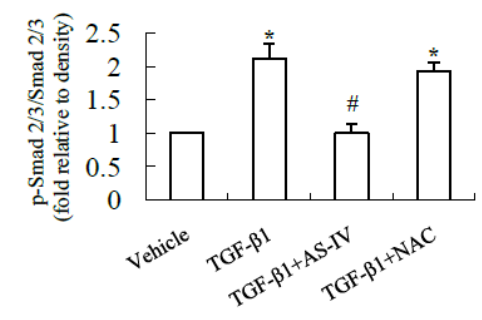

$\mathrm{F}$

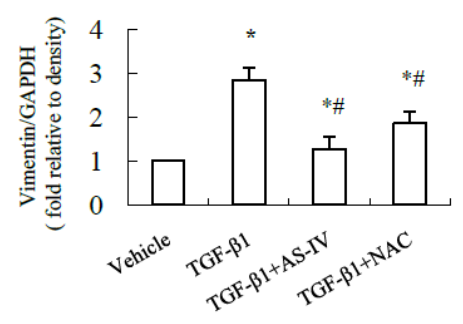

Fig. 5. Effects of Astragaloside IV on reactive oxygen species (ROS) production, activation of Smad2/3 and expression of Smad7 in TGF- $\beta 1$-treated HMrSV5 cells. Cells were divided into a vehicle group (cells treated with $0.1 \%$ DMSO), a TGF- $\beta 1$ group (cells treated with $10 \mathrm{ng} / \mathrm{ml}$ TGF- $\beta 1$ ), an AS-IV + TGF- $\beta 1$ group (cells pretreated with AS-IV at $400 \mu \mathrm{g} / \mathrm{ml} 2 \mathrm{~h}$ prior to $2 \mathrm{ng} / \mathrm{ml}$ TGF- $\beta 1$ ) and an NAC + TGF- $\beta 1$ group (cells pretreated with NAC at $100 \mathrm{nM} 2 \mathrm{~h}$ prior to $2 \mathrm{ng} / \mathrm{ml}$ TGF- $\beta 1$ ). After incubation for $24 \mathrm{~h}$, DCFH-DA fluorescence in cultured cells was analyzed by fluorescence microscopy (A). The quantification of fluorescence intensity is presented in the bar graphs (B). Representative immunoblots of p-Smad, Smad2/3, Smad7 and Vimentin are shown in (C), and GAPDH served as a loading control. Relative intensity of p-Smad/Smad2/3, Smad7/ GAPDH and vimentin/GAPDH is shown from (D) to (F). ${ }^{*} \mathrm{p}<0.05$ vs. vehicle group, $\# \mathrm{p}<0.05$ vs. TGF- $\beta 1$ group, $\mathrm{n}=3$.

the expression levels of Smad7 in the stable cell lines. Overexpression of Smad7 resulted in decreased EMT in TGF $\beta 1$-treated HMrSV5 cells. In addition, the effect of AS-IV on the downregulated expression of vimentin in TGF- $\beta 1$-treated cells was partially reversed by knockdown of Smad7 in HMrSV5 cells (Fig. 6A-6C). These results were confirmed by the transwell migration assay (Fig. 6D and 6E). All the above results suggested that Smad7 plays a key role in the inhibitory effect of AS-IV on TGF $\beta 1$-induced EMT.

\section{Discussion}

$P D$ remains the initial treatment for patients with end-stage renal disease. In the past few years, it has become clear that TGF $\beta 1$-induced EMT is a crucial process in the development of PD-related complications such as recurrent episodes of peritonitis, inadequate dialysis 


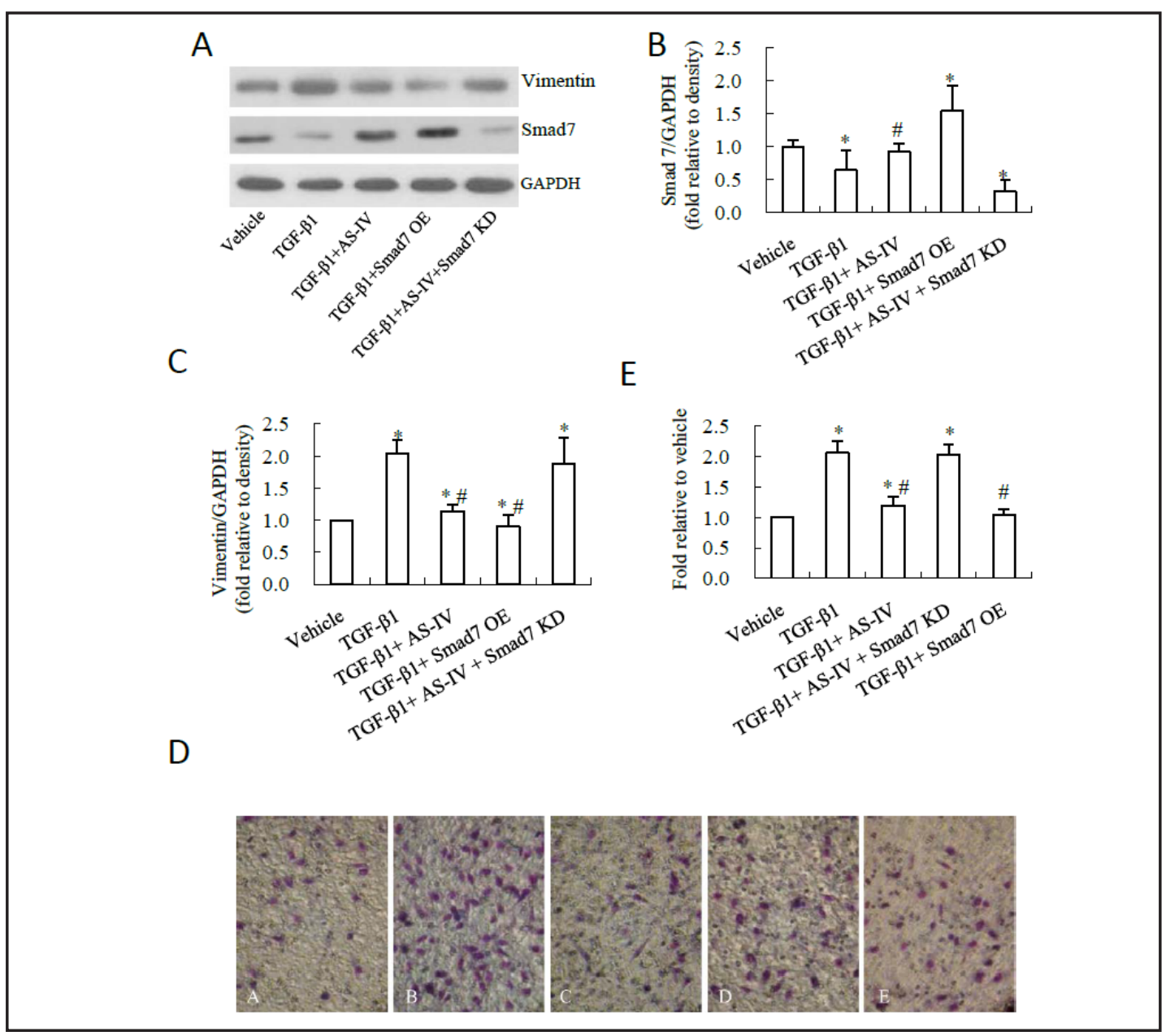

Fig. 6. Effect of Smad7 on TGF- $\beta 1$-induced EMT in HMrSV5 cells. Cells were divided into a vehicle group (cells treated with $0.1 \%$ DMSO), TGF- $\beta 1$ group (cells treated with $2 \mathrm{ng} / \mathrm{ml}$ TGF- $\beta 1$ ), TGF- $\beta 1+$ AS-IV group (cells pretreated with AS-IV at $400 \mu \mathrm{g} / \mathrm{ml} 2 \mathrm{~h}$ prior to $2 \mathrm{ng} / \mathrm{ml}$ TGF- $\beta 1$ ), TGF- $\beta 1+$ Smad7 overexpression(OE) group (after Smad7 enforced expression using a Smad7-overexpression lentivirus, cells were treated with 2 ng/ml TGF- $\beta 1$ ) and TGF- $\beta 1$ + AS-IV + Smad7 knockdown(KD) group (after Smad7 deletion using a Smad7-inhibitor lentivirus, cells were pretreated with AS-IV at $400 \mu \mathrm{g} / \mathrm{ml} 2 \mathrm{~h}$ prior to $2 \mathrm{ng} / \mathrm{ml}$ TGF- $\beta 1$ ). After incubation for $24 \mathrm{~h}$, the levels of vimentin, Smad7 and GAPDH were analyzed by western blot (A-C). The migrating cells were detected by Giemsa staining (D) (A. vehicle group; B. TGF- $\beta 1$ group; C. TGF- $\beta 1+$ AS-IV group; D. TGF- $\beta 1+$ AS-IV + Smad7 KD group; E. TGF- $\beta 1+S m a d 7$ OE group). The quantification of the migrating cells is expressed graphically as a relative fold increase of the vehicle (E). Six random fields for each insert were counted, and three independent experiments were performed in each group. * $<<0.05$ vs. vehicle group, $\# \mathrm{p}<0.05$ vs. TGF- $\beta 1$ group, $\mathrm{n}=3$.

and ultrafiltration failure $[10,25,26]$. Currently, no appropriate methods to block TGF $\beta 1$ induced EMT have been approved in clinical practice. Most studies thus far have focused on herbal medicine as an alternative treatment. Astragaloside IV (AS-IV) is a cycloartane triterpene saponin with a clear formula, which are the main active ingredients of Astragalus membranaceus [11]. Emerging evidences have indicated that AS-IV shows anti-fibrotic effects on organ fibrosis [13-16]. However, this macromolecule's effect on TGF $\beta 1$-induced EMT of human peritoneal mesothelial cells has not been clearly delineated.

In this study, we first assessed the role of AS-IV during TGF- $\beta 1$-induced EMT in HMrSV5 cells. TGF- $\beta$-induced activation of the receptor complex leads to the activation of Smad2 and Smad3 through phosphorylation of the type I receptors. Next, trimers consisting of 


\section{Cellular Physiology Cell Physiol Biochem 2015;37:43-54 \\ \begin{tabular}{l|l} 
and Biochemistry Published online: August 12, 2015 & $\begin{array}{l}\text { C) 2015 S. Karger AG, Basel } \\
\text { www.karger.com/cpb }\end{array}$ \\
\hline
\end{tabular} \\ Zhang et al.: AS-IV Against the TGF- $\beta 1$-Induced EMT}

phosphorylated Smad2/3 and Smad4 translocate to the nucleus, where they cooperate with transcription factors such as Snail and Twist to repress the expression of epithelial markers and activate the expression of mesenchymal markers. This signaling is referred to as TGF$\beta$-activated Smad signaling in EMT [27-29]. Similar to previous studies, $2 \mathrm{ng} / \mathrm{ml}$ of TGF- $\beta 1$ decreased expression of epithelial markers, increased expression of mesenchymal markers, which was accompanied by an increase in Smad2/3 activation (increased expression of phospho-Smad2/3) in HMrSV5 cells. A western blot assay revealed that, compared to the TGF- $\beta 1$-treated cells, AS-IV pre-treatment resulted in decreased expression of mesenchymal markers and phospho-Smad2/3 (Fig. 3A-3F). Furthermore, AS-IV treatment also decreased Snail1 and Snail2 (downstream of phosphorylated Smad2/3) at the mRNA level (Fig. 3G and $3 \mathrm{H})$. These results indicated that the inhibitory effect of AS-IV on TGF- $\beta 1$-induced HMrSV5 cell EMT is mediated by the suppression of Smad2/3 activation, which is consistent with previously published data on other epithelial cells $[12,30]$.

The inhibitory activity of Smad7 also serves as a key regulator for TGF- $\beta 1$ signaling. Smad7 interferes with TGF- $\beta 1 /$ Smad signaling through the recruitment of E3 ubiquitin ligases leading to the degradation of receptors, and through an interaction with GADD34 that inactivates Smad2/3 to inhibit downstream signals of TGF- $\beta 1$ [31-34]. In this study, we reported the signature of AS-IV treatment in Smad7 expression and determined that Smad7 plays an important role in the inhibitory effect of AS-IV on TGF- $\beta 1$-induced EMT. Firstly, increased Smad7 expression induced by AS-IV correlated with decreased EMT and activation of Smad2/3 in a dose-dependent manner. Secondly, the high expression level of Smad7 did not correlate with the expression of TGF- $\beta$ receptors (Fig. 4). These results indicated that the inhibitory effect of AS-IV on TGF- $\beta 1$-induced HMrSV 5 cell EMT is mediated by the enhanced expression of Smad 7.

Oxidative stress plays a vital role in TGF- $\beta 1 /$ Smad signaling, and reactive oxygen species (ROS) are the major free radical source of this stress. TGF- $\beta 1$ stimulates the production of ROS in various types of cells, while ROS activate TGF- $\beta$ and mediate many of TGF- $\beta$ 's fibrogenic effects [35-38]. Recent literature has provided evidence suggesting that ROS generation induces EMT in lung epithelium $[39,40]$. On the other hand, AS-IV was reported as an antioxidant agent that could ameliorate podocyte apoptosis and prevent mesangial cell injury by inhibiting ROS production and oxidative stress $[41,42]$. To investigate the relationship between EMT and oxidative stress in HMrSV5 cells and the role of the antioxidant effect of AS-IV on TGF- $31 /$ Smad signaling and EMT, we detected ROS generation by DCFHDA staining and the expression of a mesenchymal marker (vimentin) and phosphorylated Smad2/3 by a western blot assay. As shown in Fig. $5 \mathrm{~A}$ and $5 \mathrm{~B}$, after treatment with TGF- $\beta 1$, significantly increased ROS generation was found in HMrSV5 cells. AS-IV recovered TGF$\beta 1$-induced increases in ROS, similar to the effect of NAC (the ROS scavenger), which is consistent with previous studies. Furthermore, AS-IV also significantly decreased phosphoSmad2/3 levels and EMT induced by TGF- $\beta 1$ and increased expression of Smad 7 in HMrSV5 cells. In contrast, NAC treatment did not impair Smad2/3 activation and EMT (Fig. 5C-5F). These results indicated that TGF- $\beta 1$-induced EMT in HMrSV5 cells is ROS-independent.

To further confirm the role of Smad 7 in the inhibitory effect of AS-IV on TGF- $\beta 1$-induced EMT, we generated Smad7 overexpression and Smad7 knockdown cell lines (the expression of Smad 7 was confirmed in Fig. 6). As shown in Fig. 6A-6C, enforced Smad7 expression resulted in decreased expression of vimentin induced by TGF- $\beta 1$. The knockdown of Smad7 restored the suppressive effect of As-IV on TGF- $\beta 1$-induced EMT. On the other hand, EMT is an evolutionarily-conserved development process, accompanied by the loss of epithelial polarity and the gain of motile characteristics of mesenchymal cells. Therefore, enhanced cell migration is implicated in the progression of EMT [43]. In this study, we found that TGF- $\beta 1$ increased the percentage of transmigrated cells compared to control cells, verifying its capacity to induce EMT. AS-IV treatment and enforced Smad 7 expression reduced transmigrated cells compared with TGF- $\beta 1$-treated cells. The knockdown of Smad 7 in HMrSV 5 cells resulted in increased cell transmigration in cells treated with AS-IV and TGF- $\beta 1$ (Fig. 6D and 6E). These results verified the role of Smad7 in the effect of AS-IV on EMT.

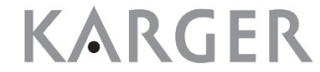




\section{Cellular Physiology Cell Physiol Biochem 2015;37:43-54 \begin{tabular}{l|l} 
DOI: 10.1159/000430332 & (c) 2015 S. Karger AG, Basel
\end{tabular} www.karger.com/cpb \\ Zhang et al.: AS-IV Against the TGF- $\beta 1$-Induced EMT}

In our study, the effects of AS-IV on the TGF- $\beta 1 /$ Smad signaling pathway and TGF- $\beta 1$ induced EMT have been studied in HMrSV5 cells. These findings provide some novel findings in HMrSV5 cells. First, TGF- $\beta 1$ is a signature of EMT in peritoneal mesothelial cells. Second, the findings of this study establish a direct link between AS-IV and TGF- $\beta 1$ during EMT. Finally, this is the first study to describe Smad 7 as a direct target of AS-IV. Our findings also suggest that AS-IV may be a good therapeutic agent for the control of PF in terms of EMT.

\section{Acknowledgements}

This work was supported by grants from the National Natural Science Foundation of China (No. 81473606, No. 81273715,No.81300631), the Natural Science Foundation of Jiangsu Province (BK2011869,BK20131036)and the Scientific Research Foundation for Traditional Chinese Medicine Talent of Jiangsu Province (No. LJ200904).

\section{Disclosure Statement}

All authors have no conflicts of interest to declare.

\section{References}

1 Collins AJ, Foley RN, Chavers B, Gilbertson D, Herzog C, Johansen K, Kasiske B, Kutner N, Liu J, St Peter W, Guo H, Gustafson S, Heubner B, Lamb K, Li S, Li S, Peng Y, Qiu Y, Roberts T, Skeans M, Snyder J, Solid C, Thompson B, Wang C, Weinhandl E, Zaun D, Arko C, Chen SC, Daniels F, Ebben J, Frazier E, Hanzlik C, Johnson R, Sheets D, Wang X, Forrest B, Constantini E, Everson S, Eggers P, Agodoa L: United States Renal Data System 2011 Annual Data Report: Atlas of chronic kidney disease and end-stage renal disease in the United States. Am J Kidney Dis 2012;59:A7, e1-420.

2 Davies SJ, Phillips L, Griffiths AM, Russell LH, Naish PF, Russell GI: What really happens to people on longterm peritoneal dialysis? Kidney Int 1998;54:2207-2217.

3 Williams JD, Craig KJ, Topley N, Von Ruhland C, Fallon M, Newman GR, Mackenzie RK, Williams GT; Peritoneal Biopsy StudyGroup: Morphologic changes in the peritoneal membrane of patients with renal disease. J Am Soc Nephrol 2002;13:470-479.

4 Devuyst 0, Margetts PJ, Topley N: The pathophysiology of the peritoneal membrane. J Am Soc Nephrol 2010;21:1077-1085.

5 Shimaoka T, Hamada C, Kaneko K, Io H, Sekiguchi Y, Aruga S, Inuma J, Inami Y, Hotta Y, Horikoshi S, Kumasaka T, Tomino Y: Quantitative evaluation and assessment of peritoneal morphologic changes in peritoneal dialysis patients. Nephrol Dial Transplant 2010;25:3379-3385.

6 Smit W, Schouten N, van den Berg N, Langedijk MJ, Struijk DG, Krediet RT ;Netherlands Ultrafiltra 7 tion Failure Study Group: Analysis of the prevalence and causes of ultrafiltration failure during long-term perito-neal dialysis: a cross-sectional study. Perit Dial Int 2004;24:562-570.

7 Farhat K, Stavenuiter AW, Beelen RH, Ter Wee PM: Pharmacologic targets and peritoneal membrane remodeling. Perit Dial Int 2014;34:114-123.

8 Diao JN, Sheng MX, Zhu XX, Wang NJ, Zhu CL, He WM: Huangqi (Astragalus membranaceus) injections could improve the dialysis efficiency and reduce peritoneal fibrosis in high permeable peritoneal dialysis treated rats (In Chinese). Nan Jing Zhong Yi Yao Da Xue Xue Bao 2011;27:58-62.

9 Yang HT, Shang YC, Cao SL, Dou YT, Huang Y: Effect of shenshuning recipe on the extracellular matrix accumulation of the peritoneal fibrosis rats (in Chinese). Zhongguo Zhong Xi Yi Jie He Za Zhi 2013;33:16831689.

10 Li Z, Zhang L, He W, Zhu C, Yang J, Sheng M: Astragalus membranaceus inhibits peritoneal fibrosis via monocyte chemoattractant protein (MCP)- 1 and the transforming growth factor- $\beta 1$ (TGF- $\beta 1$ ) pathway in rats submitted to peritoneal dialysis. Int J Mol Sci 2014; 15:12959-12971.

11 Polat E, Bedir E, Perrone A, Piacente S, Alankus-Caliskan 0:Triterpenoid saponins from Astragalus wiedemannianus Fischer. Phytochemistry 2010;71:658-662. 


\section{Cellular Physiology Cell Physiol Biochem 2015;37:43-54 \begin{tabular}{l|l|l}
\hline DOI: 10.1159/000430332 & O $2015 \mathrm{~S}$. Karger AG, Base \\
wwww.karger.com/cpb
\end{tabular} \\ Zhang et al.: AS-IV Against the TGF- $\beta 1$-Induced EMT}

12 Chen X, Peng LH, Li N, Li QM, Li P, Fung KP, Leung PC, Gao JQ: The healing and anti-scar effects of astragaloside IV on the wound repair in vitro and in vivo. J Ethnopharmacol 2012;139:721-727.

13 Xu W, Shao X, Tian L, Gu L, Zhang M, Wang Q, Wu B, Wang L, Yao J, Xu X, Mou S, Ni Z:Astragaloside IV ameliorates renal fibrosis via the inhibition of mitogen-activated protein kinases and antiapoptosis in vivo and in vitro. J Pharmacol Exp Ther 2014;350:552-562.

14 Li X, Wang X, Han C, Wang X, Xing G, Zhou L, Li G, Niu Y: Astragaloside IV suppresses collagen production of activated hepatic stellate cells via oxidative stress-mediated p38 MAPK pathway. Free Radic Biol Med 2013;60:168-176.

15 Chen P, Xie Y, Shen E, Li GG, Yu Y, Zhang CB, Yang Y, Zou Y, Ge J, Chen R, Chen H: Astragaloside IV attenuates myocardial fibrosis by inhibiting TGF- $\beta 1$ signaling in coxsackievirus B3-induced cardiomyopathy. Eur J Pharmacol 2011;658:168-174.

16 Wang L, Chi YF, Yuan ZT, Zhou WC, Yin PH, Zhang XM, Peng W: Astragaloside IV inhibits the upregulation of Wnt/ $\beta$-catenin signaling in rats with unilateral ureteral obstruction. Cell Physiol Biochem. 2014;33:1316-1328.

17 Lamouille S, Xu J, Derynck R: Molecular mechanisms of epithelial-mesenchymal transition. Nat Rev Mol Cell Biol 2014;15:178-196.

18 Xu J, Lamouille S, Derynck R: TGF-beta-induced epithelial to mesenchymal transition. Cell Res 2009;19:156-172.

19 Strippoli R, Loureiro J, Moreno V, Benedicto I, Pérez Lozano ML, Barreiro O, Pellinen T, Minguet S, Foronda M, Osteso MT, Calvo E, Vázquez J, López Cabrera M, Del Pozo MA: Caveolin-1 deficiency induces a MEKERK1/2-Snail-1-dependent epithelial-mesenchymal transition and fibrosis during peritoneal dialysis. EMBO Mol Med 2014;7:102-123.

20 Yáñez-Mó M, Lara-Pezzi E, Selgas R, Ramírez-Huesca M, Domínguez-Jiménez C, Jiménez-Heffernan JA, Aguilera A, Sánchez-Tomero JA, Bajo MA, Alvarez V, Castro MA, del Peso G, Cirujeda A, Gamallo C, SánchezMadrid F, López-Cabrera M : Peritoneal dialysis and epithelial-to-mesenchymal transition of mesothelial cells. N Engl J Med 2003;348:403-413.

21 Pletinck A, Vanholder R, Veys N, Van Biesen W: Protecting the peritoneal membrane: factors beyond peritoneal dialysis solutions. Nat Rev Nephrol 2012;8:542-550.

22 Goodlad C, Brown EA: Encapsulating peritoneal sclerosis: what have we learned? Semin Nephrol 2011;31:183-198.

23 Gonzalez DM, Medici D: Signaling mechanisms of the epithelial-mesenchymal transition. Sci Signal 2014;7:re8.

24 Okado T, Terada Y, Tanaka H, Inoshita S, Nakao A, Sasaki S: Smad7 mediates transforming growth factorbeta-induced apoptosis in mesangial cells. Kidney Int 2002;62:1178-1186.

25 Nakamoto H, Kawaguchi Y, Suzuki H: Is technique survival on peritoneal dialysis better in Japan? Perit Dial Int 2006;26:136-143.

26 Strippoli R, Benedicto I, Perez Lozano ML, Pellinen T, Sandoval P, Lopez-Cabrera M, del Pozo MA: Inhibition of transforming growth factor-activated kinase 1 (TAK1) blocks and reverses epithelial to mesenchymal transition of mesothelial cells. PLoS One 2012;7:e31492.

27 Pang L, Li Q, Wei C, Zou H, Li S, Cao W, He J, Zhou Y, Ju X, Lan J, Wei Y, Wang C, Zhao W, Hu J, Jia W, Qi Y, Liu F, Jiang J, Li L, Zhao J, Liang W, Xie J, Li F:TGF- $\beta 1 /$ Smad signaling pathway regulates epithelial-tomesenchymal transition in esophageal squamous cell carcinoma: in vitro and clinical analyses of cell lines and nomadic Kazakh patients from northwest Xinjiang, China. PLoS One 2014;9:e112300.

28 Geng J, Fan J, Ouyang Q Zhang X, Zhang X, Yu J, Xu Z, Li Q, Yao X, Liu X, Zheng J: Loss of PPM1A expression enhances invasion and the epithelial-to-mesenchymal transition in bladder cancer by activating the TGF- $\beta$ /Smad signaling pathway. Oncotarget 2014;5:5700-5711.

29 Rodrigues-Diez R, Rodrigues-Diez RR, Lavoz C, Carvajal G, Droguett A, Garcia-Redondo AB, Rodriguez I, Ortiz A, Egido J, Mezzano S, Ruiz-Ortega M: Gremlin activates the Smad pathway linked to epithelial mesenchymal transdifferentiation in cultured tubular epithelial cells. Biomed Res Int 2014;2014:802841.

30 Wang L, Chi YF, Yuan ZT, Zhou WC, Yin PH, Zhang XM, Peng W, Cai H: Astragaloside IV inhibits renal tubulointerstitial fibrosis by blocking TGF- $\beta /$ Smad signaling pathway in vivo and in vitro. Exp Biol Med (Maywood) 2014;239:1310-1324.

31 Park SH, Jung EH, Kim GY, Kim BC, Lim JH, Woo CH:Itch E3 Ubiquitin Ligase Positively Regulates TGF- $\beta$ Signaling to EMT via Smad7 Ubiquitination. Mol Cells 2015;38:20-25. 


\section{Cellular Physiology Cell Physiol Biochem 2015;37:43-54

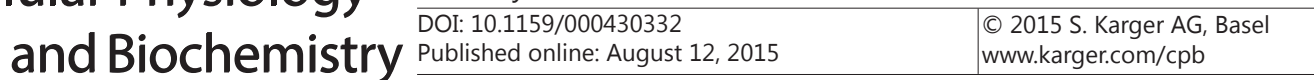 \\ Zhang et al.: AS-IV Against the TGF- $\beta 1$-Induced EMT}

32 Ka SM, Yeh YC, Huang XR, Chao TK, Hung YJ, Yu CP, Lin TJ, Wu CC, Lan HY, Chen A: Kidney-targeting Smad7 gene transfer inhibits renal TGF- $\beta$ /MAD homologue (SMAD) and nuclear factor $\kappa B(N F-\kappa B)$ signalling pathways, and improves diabetic nephropathy in mice. Diabetologia 2012;55:509-519.

33 Yan X, Zhang J, Pan L, Wang P, Xue H, Zhang L, Gao X, Zhao X, Ning Y, Chen YG: TSC-22 promotes transforming growth factor $\beta$-mediated cardiac myofibroblast differentiation by antagonizing Smad7 activity. Mol Cell Biol 2011;31:3700-3709.

34 Kokkinakis DM, Liu X, Chada S, Ahmed MM, Shareef MM, Singha UK, Yang S, Luo J:Modulation of gene expression in human central nervous system tumors under methionine deprivation-induced stress. Cancer Res 2004;64:7513-7525.

35 Park SA, Kim MJ, Park SY, Kim JS, Lee SJ, Woo HA, Kim DK, Nam JS, Sheen YY: EW-7197 inhibits hepatic, renal, and pulmonary fibrosis by blocking TGF- $\beta$ /Smad and ROS signaling. Cell Mol Life Sci 2015;72:20232039.

36 Lu G, Xu S, Peng L, Huang Z, Wang Y, Gao X:Angiotensin II upregulates Kv1.5 expression through ROSdependent transforming growth factor-beta1 and extracellular signal-regulated kinase 1/2 signalings in neonatal rat atrial myocytes. Biochem Biophys Res Commun 2014;454:410-416.

37 Huang KT, Wu CT, Huang KH, Lin WC, Chen CM, Guan SS, Chiang CK, Liu SH: Titanium Nanoparticle Inhalation Induces Renal Fibrosis in Mice via an Oxidative Stress Upregulated Transforming Growth Factor- $\beta$ Pathway. Chem Res Toxicol 2015;28:354-364.

38 Choi YJ, Kim da H, Kim SJ, Kim J, Jeong SI, Chung CH, Yu KY, Kim SY: Decursin attenuates hepatic fibrogenesis through interrupting TGF-beta-mediated NAD(P)H oxidase activation and Smad signaling in vivo and in vitro. Life Sci 2014;108:94-103.

39 Hu Y, He K, Wang D, Yuan X, Liu Y, Ji H, Song J:TMEPAI regulates EMT in lung cancer cells by modulating the ROS and IRS-1 signaling pathways. Carcinogenesis 2013;34:1764-72.

40 Felton VM, Borok Z, Willis BC: N-acetylcysteine inhibits alveolar epithelial-mesenchymal transition. Am J Physiol Lung Cell Mol Physiol 2009;297:L805-812.

41 Gui D, Guo Y, Wang F, Liu W, Chen J, Chen Y, Huang J, Wang N: Astragaloside IV, a novel antioxidant, prevents glucose-induced podocyte apoptosis in vitro and in vivo. PLoS One 2012;7:e39824.

42 Sun L, Li W, Li W, Xiong L, Li G, Ma R:Astragaloside IV prevents damage to human mesangial cells through the inhibition of the NADPH oxidase/ROS/Akt/NF- $\mathrm{BB}$ pathway under high glucose conditions. Int J Mol Med 2014;34:167-176.

43 Bae SY, Kim HJ, Lee KJ, Lee K: Translationally Controlled Tumor Protein induces epithelial to mesenchymal transition and promotes cell migration, invasion and metastasis. Sci Rep 2015;5:8061. 